\title{
La perífrasis soler + INFINITIVo a la luz del latín (II): Lecturas y valores de soleo+INFINITIVO
}

\author{
Esther Artigas Álvarez ${ }^{1}$ \\ Universidad de Barcelona, España
}

\begin{abstract}
Resumen
En este trabajo se ofrece un panorama amplio de las lecturas y valores que desarrolla en latín la construcción soleo + INF, visto desde la perspectiva de la Gramática de construcciones diacrónica. Los testimonios aportados y el análisis de los distintos factores implicados en la interpretación de esta perífrasis revelan que en su origen no se sitúa la expresión del aspecto habitual-frecuentativo que los modelos tradicionales le reconocen, sino un valor caracterizador básico que cabe emplazar en el ámbito del aspecto continuo. Por otra parte, las posibilidades estructurales y el comportamiento de soleo + INF en latín permiten establecer un marco de referencia interesante para explicar algunos usos particulares de soler + INF en los primeros estadios del español.
\end{abstract}

Palabras clave: latín, soleo+INFINITIVO, perífrasis verbal, aspecto y modalidad, gramática de construcciones diacrónica. 
THE PERIPHRASIS SOLER + INFINITIVE IN THE LIGHT OF LATIN (II):

READINGS AND VALUES OF SOLEO+INFINITIVE

Abstract

This paper offers a broad overview, seen from the perspective of Diachronic Construction Grammar, of the readings and values developed in Latin by the construction soleo+INF. The evidence provided and the analysis of the various factors involved in the interpretation of this periphrasis show that its original and basic value is not the expression of habitual aspect, as traditional models maintain, but a typifying meaning that should be considered in the framework of the continuous aspect. On the other hand, the structural possibilities and the behavior of soleo+INF in Latin allow to set an interesting reference framework to explain some particular uses of soler+ INF in the earliest stages of the Spanish language.

Keywords: Latin, soleo+INFINITIVE, verbal periphrasis, aspect and modality, diachronic construction Grammar.

Recibido: 06/06/19 Aceptado: 04/08/19

\section{INTRODUCCIÓN}

La tradicional inclusión del verbo latino soleo en el grupo de los que se construyen con un infinitivo en función de objeto directo (Bassols 1956: I $\$ 374 / 1$ a) ha dejado paso, en los últimos años, a la categorización de este verbo como auxiliar del infinitivo (Pinkster 2015: 210-212) en construcciones perifrásticas de aspecto habitual (Haverling 2010: 444).

El objetivo de este trabajo es ofrecer una presentación amplia de los valores que la construcción soleo+INF despliega a lo largo de la historia del latín, mediante la discusión de los testimonios y el análisis de los distintos factores implicados en su interpretación. Además, los resultados obtenidos nos han de permitir establecer un marco de referencia válido para explicar algunos usos particulares de soler+INF en los primeros estadios de la historia del español y en su posterior desarrollo.

En la conceptuación aspectual de esta perífrasis se detectan no pocos problemas de ambigüedad terminológica y frecuentes equívocos, a menudo relacionados con las dificultades que comporta, en general, el establecimiento y la organización de las distintas variedades aspectuales. Por ello, aunque sin 
ánimo de profundizar en la discusión teórica, establecemos aquí brevemente los presupuestos básicos y las líneas fundamentales de acercamiento a las posibilidades de clasificación aspectual de soleo+INF.

Por una parte, tal como hace Camus (2004: 521) sobre la base de los trabajos de Klein (1982: 537), Bertinetto (1986: 139-162) y García Fernández (2004: 13-95), partimos de la distinción central que se opera, dentro del aspecto de manera, entre eventos inconclusos y concluidos, y nos centramos, atendiendo a las características y al comportamiento específico de soleo+INF en latín, en las subvariedades aspectuales habitual y continua del aspecto Imperfecto y, para la expresión de los eventos concluidos, en las variedades aspectuales de perfecto y aoristo.

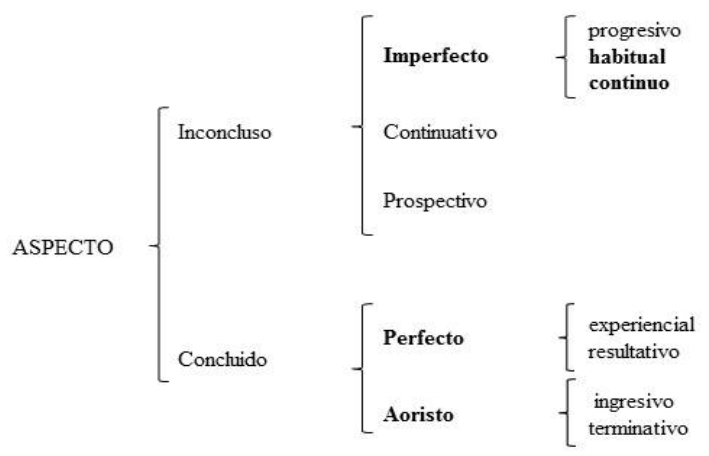

Pero, además, tomaremos también en consideración, en vista de las posibilidades construccionales de la perífrasis, la perspectiva cuantificacional del aspecto defendida por Dik (1997: 222), de acuerdo con la cual: 1) el aspecto habitual debe incluirse como subvariedad del aspecto cuantificacional, en calidad de operador o mecanismo gramatical que permite definir un estado de cosas a través de su cuantificación; 2) considerando la frecuencia que se predica de un estado de cosas, dentro del aspecto cuantificacional se distinguen variedades aspectuales semelfactivas, iterativas, frecuentativas y distributivas.

En el desarrollo de los valores de soleo+INF juega un papel fundamental la noción de construcción, que entendemos en el sentido que se da a este concepto en la Gramática de construcciones: una construcción gramatical es la unión de una forma con un significado convencionalizado en el uso (Goldberg 2006). Dado que el nuestro es un estudio de naturaleza histórica, adoptamos como modelo de análisis el facilitado por la Gramática de construcciones diacrónica (Traugott-Trousdale 2013; Barđdal-Gildea 2015). La continuidad entre gramática y léxico, y los límites difusos que este paradigma establece entre categorías y conceptos gramaticales, abren 
posibilidades interesantes en la explicación de los cambios semánticos y formales que afectan a las construcciones en general y, en particular, a la determinación en latín de las incompatibilidades construccionales del verbo soleo.

Metodológicamente, nuestro trabajo está basado en una aproximación al estudio lingüístico basado en el uso. Los ejemplos han sido extraídos de los corpus documentales latinos y españoles que consignamos en la bibliografía. Por su parte, la traducción de los ejemplos latinos que aportamos es básicamente instrumental y debe su literalidad al propósito de no condicionar con ella una determinada lectura o interpretación de los testimonios.

Al margen de esta introducción, el trabajo se estructura en cuatro apartados. El primero (apartado 2) está dedicado a las variedades aspectuales y modales implicadas en la construcción de soleo+INF. Se analizan los puntos de contacto entre la lectura habitual y la frecuentativa, así como los casos de intersección de la perífrasis en el ámbito de lo modal. A continuación, en el apartado 3 nos ocupamos de los colocados léxicos, esto es, de los elementos de concurrencia usual en el entorno construccional de soleo. Así, revisamos la teórica incompatibilidad en latín de este auxiliar con algunos tipos de predicado, la clase de sujeto que selecciona la perífrasis y la asociación que se da entre la semántica de esta construcción y las estructuras sintácticas en que participa. En la sección 4 presentamos algunos casos de la interacción tempo-aspectual que se produce cuando soleo se encuentra en tiempo pasado; esbozamos también la cuestión controvertida, que desarrollamos en ArtigasCabré (en prensa), de su empleo latino en las formas del pasado perfectivo, y las correspondientes dificultades de categorización de la perífrasis que ello supone. Finalmente, en el apartado de conclusiones, recapitulamos sobre lo expuesto y, a partir de las lecturas y valores de soleo+INF desarrollados en latín, planteamos una representación radial de los mismos.

\section{VARIEDADES ASPECTUALES Y MODALES}

\subsection{HÁBITO, ITERACIÓN Y FRECUENCIA}

Para soleo+INF, puede documentarse el valor aspectual de habitualidad, en los términos teóricos establecidos en la introducción, en el latín de todas las épocas. En principio, las condiciones no difieren de las que se dan en la correspondiente perífrasis española. Ambas requieren que el evento 
representado por el infinitivo, para ser concebido como habitual y poder focalizar su desarrollo, sea de naturaleza iterable y, en consecuencia, incompatible con su conclusión (Bertinetto 1997: 61-93). Ello explica el uso mayoritario de soleo+INF en los tiempos de morfología imperfectiva (ejemplos 1 y 2 ).

(1) nam bellicas laudes solent quidam extenuare verbis, easque detrahere ducibus, communicare cum multis, ne propriae sint imperatorum. (Cicero, Pro Marcello 6)

'En efecto, suelen algunos minimizar las glorias bélicas con sus palabras, hurtárselas a los jefes, compartirlas con muchos, de manera que no sean exclusivas de los generales'.

Al final de la Aulularia, Estrobilo no tiene ninguna intención de devolverle a su amo el oro que este le ha entregado para que lo que custodiara. Por ello, cuando Licónides se lo reclama, el esclavo juega al despiste escudándose en su hábito de decir bobadas.

(2) LYC. Quod modo fassu's esse in arca. / ST. Soleo hercle ego garrire nugas. (Plautus, Aulularia 829-830)

'LIC. El [oro] que dijiste hace un momento que tenías en el arca. / ES. Por Hércules, yo suelo decir bobadas'.

Seguramente, desde una óptica actual, la lectura más inmediata que hacemos de este par de ejemplos consiste en focalizar los eventos 'atenuar las alabanzas bélicas' o 'decir bobadas' y deducir de ellos lo que está en la base de la habitualidad, es decir, la existencia de una situación que ha ocurrido al menos una vez y que es susceptible de repetirse. Pero, además, y pese a no tener una cuantificación explícita, tendemos, por implicación pragmática, a interpretar la potencial iteración del evento como frecuencia efectiva, en el sentido de que, en (1), los que minimizan las alabanzas bélicas, lo hacen 'a menudo' o que, en (2), yo digo bobadas 'con frecuencia', es más, 'con bastante frecuencia' (Gavarró y Laca 2002: 2704). Como hemos señalado, esta doble posibilidad es, en el plano teórico, la que está en la base de la clasificación de la habitualidad bien como variedad del aspecto de manera, bien como variedad del aspecto cuantificacional (Dik 1997: 222).

Ahora bien, de hecho, lo que define la habitualidad no es propiamente la frecuencia efectiva sino la utilización del evento iterable para definir al sujeto desde la tipicidad, el hábito o la costumbre. Ello quiere decir que los ejemplos (1) y (2) permiten lecturas ajustadas al margen de la frecuencia, en el sentido de que hay oradores 'cuya costumbre es' atenuar las alabanzas bélicas o que yo 'tengo por costumbre' decir bobadas. 
Con relación al ejemplo (2) es ilustrativo otro pasaje plautino (3), donde tenemos la utilización de la misma expresión soleo garrire nugas, esta vez deconstruida, repartida en las intervenciones de dos personajes. Así, cuando Planesia, a propósito de una afirmación disparatada de Gorgojo sobre un anillo, le espeta nugas garris 'dices bobadas', el parásito le replica escuetamente: soleo, esto es, 'lo tengo por costumbre, me dedico a ello, es algo propio de mí, es mi oficio'.

(3) PL. Nugas garris. / CV. Soleo: nam propter eas uiuo facilius. (Plautus, Curculio 603-604)

'PL. Dices bobadas. / CU. Lo tengo por costumbre: es que gracias a ellas mi vida es más fácil'.

Es evidente que, en este contexto, lo relevante no es tanto la iteración del evento de la que se pueda inferir la habitualidad cuanto la evidencialidad del hábito típico que define al personaje.

Común y compatible con ambas lecturas, esto es, el hábito o costumbre y la frecuencia generalmente asociada a la habitualidad, es el valor caracterizador de la perífrasis soleo+INF. Naturalmente, el hábito de decir bobadas y gastar bromas puede llevar a la caracterización del sujeto como un bromista. Pero también la cuantificación frecuentativa puede utilizarse para describir una cualidad inherente del sujeto y servir como característica definitoria del mismo (Fernández de Castro 1999: 315-317). Volveremos a lo largo del trabajo sobre este valor que consideramos básico de la perífrasis.

\subsection{El CONTEXTO SEMÁNTICO}

En la caracterización de los valores de soleo+INF se hace imprescindible evaluar la función del contexto gramatical en el que se desarrolla la perífrasis. Ello supone ampliar la construcción más allá de la secuencia formada por los verbos auxiliar y auxiliado para dar cabida a otros elementos sintáctica y semánticamente vinculados a ella.

Así, en latín, cuando la habitualidad es hábito o costumbre, estas nociones se ven naturalmente avaladas por contextos en los que aparecen verbos y expresiones que refuerzan esa idea de costumbre: mos, moris 'manera, costumbre' en el ejemplo (4); usus 'uso, práctica' en el (5); el verbo consuesco 'acostumbrar' y solitus 'acostumbrado', participio del verbo soleo, en (6); o el abstracto consuetudo 'hábito' y el verbo utor 'usar' en (7).

(4) Si dixero mendacium, solens meo more fecero. (Plautus, Amphitruo 198) 
'Si miento, obraré según suelo de acuerdo con mi costumbre'.

(5) Post transacta sollemnia dimissa plebe, quo usu solet nobis renuntiare quae uiderit [...]. (Tertullianus, De anima 9)

'Después de efectuados los ritos, cuando la gente ya se había ido, [la hermana], de acuerdo con su práctica de soler explicarnos las visiones que ha tenido [...]'.

(6) Quid, tu idem mihi uis fieri, quod erus consueuit tibi? / Si ille te comprimere solitust, hic noster nos non solet. (Plautus, Rudens 10741075)

¿Tú qué quieres? ¿que me haga lo que tu amo acostumbra contigo? Si él tiene la costumbre de darte, el nuestro a nosotros no suele".

(7) quare quoniam mihi levius quoddam onus imponitis neque ex me de oratoris arte sed de hac mea, quantulacumque est, facultate quaeritis, exponam vobis [...] rationem consuetudinis meae, qua quondam solitus sum uti, cum mihi in isto studio versari adulescenti licebat. (Cicero, De oratore 1, 135)

'Por lo tanto, ya que me imponéis una tarea más ligera al preguntarme, no acerca del orador, sino sobre esta habilidad mía, aun en sus modestas proporciones, os expondré la naturaleza de este hábito mío, que solía ejercitar cuando en mi juventud se me permitía mantener estas aficiones'.

Por otro lado, la lectura que hacemos del hábito a partir de la potencial repetición del evento se corresponde con la presencia junto a soleo+INF de un buen número de adverbios de frecuencia (Havu 1997: 324-330). Este tipo de cuantificadores no expresan cantidad absoluta - como los iterativos-sino relativa y son compatibles, por tanto, con el aspecto Imperfecto (LenciBertinetto 2000: 246). Algunos de ellos son saepe 'a menudo' en el ejemplo (8), crebriter 'con frecuencia' en (9), el distributivo quotidie 'cada día' en el ejemplo (10) y semper 'siempre' en el ejemplo (11).

(8) [...] saepe enim soleo audire Roscium. (Cicero, De oratore 1, 129) 'suelo ir a escuchar a Roscio a menudo'.

(9) nec umquam magis artis huius uiolentia nititur, quam cum scitulae formulae iuuenem quempiam libenter aspexit, quod quidem ei solet crebriter euenire. (Apuleius, Metamorphoses 3, 15)

'y nunca ejerce su arte con tanta fuerza como cuando le ha echado el ojo a alguna jovencilla bella y delicadita, lo cual suele sucederle con frecuencia'. 
(10) tam magnus ex Asia ueni quam hic candelabrus est. ad summam, quotidie me solebam ad illum metiri, et ut celerius rostrum barbatum haberem, labra de lucerna ungebam. (Petronius, Satyrica 75, 10) 'Llegué de Asia tan alto como este candelabro. Para resumir, cada día solía medirme tomándolo como referencia y, para tener barba en el rostro lo antes posible, me untaba la zona de los labios con aceite de la lucerna'.

(11) semper enim, quacumque de arte aut facultate quaeritur, de absoluta et perfecta quaeri solet. (Cicero, De oratore 3,84)

'siempre, cualquiera que sea el arte o la facultad que se plantea, suele plantearse como algo absoluto y perfecto'.

La compatibilidad de adverbios como semper con la habitualidad ha sido tratada por Lenci y Bertinetto (2000) y justificada por el carácter relacional de este tipo de adverbios en contraste con otros frecuentativos de frecuencia pura, como es, en nuestro ejemplo (8), saepe. En la lectura relacional, el adverbio simplemente establece una proporción basada en la comparación de dos eventos o situaciones. Así, semper, en el ejemplo (11), no incide de manera colectiva en el conjunto de las ocasiones en que se plantea un arte o una facultad, sino que lo hace de forma distributiva, esto es, en relación con la serie de ocurrencias efectivas de los microeventos.

También en español, la compatibilidad de siempre -y de nunca- con soler+INF y su función distribucional es ya visible en la documentación de los primeros siglos.

(12) E pues, fiio, aue duelo * / de mi mesquina que suelo / sienpre fazer el tu rruego, / quier en vera quier en juego. (Anónimo, Historia troyana en prosa y verso, c. 1270)

Aquí, una lectura colectiva de sienpre implicaría considerar el principio y el final de la situación, lo cual contradice el aspecto Imperfecto de la perífrasis. En cambio, el carácter distribucional de sienpre en relación con todas y cada una de las ocasiones en que el hijo dirige sus ruegos a su madre, sí es compatible con él, y viene expresado y especificado, en este caso, por el último de los versos 'quier en vera quier en juego'.

\subsection{LA POSIBILIDAD DE NO OCURRENCIA}

Hemos visto cómo en los ejemplos anteriores (8-12), el evento iterable se tiende a interpretar como iterado y a considerarlo, además, de frecuencia 
elevada. Sin embargo, algo más esporádicamente y más curiosamente, también la perífrasis se acompaña en latín de adverbios iterativos que comportan una frecuencia baja (ejemplos 13, 14 y 15).

(13) ipsi qui Cynica traducunt tempora pera / non numquam nummis uendere uerba solent. (Petronius, Satyrica 14, 2)

'incluso los que van por la vida con la alforja de los cínicos, a veces suelen vender las palabras por unas monedas'.

La intención manifiesta de Ascilto en el dístico de (13) es denunciar la corrupción de los miembros de la escuela cínica, a pesar de su consabido desprecio de las riquezas y de los valores materiales. Aun así, no cabe interpretar la frecuencia con que los cínicos se acaban vendiendo por unas monedas como elevada, sino que la lítotes non numquam apunta más bien al sentido de que 'no dejan de hacerlo alguna vez', de que lo hacen solo 'a veces'.

(14) uelim igitur censor meus Aemilianus respondeat, unquamne ipse soleat pedes lauare; uel, si id non negat, contendat maiorem curam munditiarum pedibus quam dentibus inpertiendam. (Apuleius, Apologia 8)

'Por tanto, yo quisiera que mi censor Emiliano responda si él suele lavarse alguna vez los pies; y, si no lo niega, que sostenga que se deben prodigar más cuidados a la limpieza de los pies que a la de los dientes'.

En (14), Apuleyo plantea la necesidad de que un orador tenga una buena higiene dental, por encima incluso de la sana costumbre de lavarse los pies. Ironía al margen, aquí el mismo carácter interrogativo del enunciado ya deja en suspenso la frecuencia del evento 'lavarse los pies', pero, además, con el adverbio unquam 'alguna vez', se restringen las posibilidades de que dicho evento se haga efectivo.

(15) quid enim necesse est, tamquam meretricem in matronarum coetum, sic uoluptatem in uirtutum concilium adducere? inuidiosum nomen est, infame, suspectum, itaque hoc frequenter dici solet a uobis, non intellegere nos, quam dicat Epicurus uoluptatem. quod quidem mihi si quando dictum est - est autem dictum non parum saepe--, etsi satis clemens sum in disputando, tamen interdum soleo subirasci. (Cicero, De finibus 2, 4, 12)

¿QQué necesidad hay de introducir el placer en la asamblea de las virtudes como una meretriz en una reunión de matronas? Es una palabra odiosa, de mala reputación, sospechosa. Y por eso vosotros soléis decir 
frecuentemente que nosotros no comprendemos de qué placer habla Epicuro. Ciertamente, si en alguna ocasión se me dice esto (y se me dice con no poca frecuencia), aunque soy bastante moderado en las discusiones, a veces suelo irritarme un poco'.

Este ejemplo ciceroniano (15) resulta interesante porque nos muestra la gama de posibilidades combinatorias de la perífrasis con los cuantificadores de frecuencia. Especialmente en el último periodo oracional, la presencia misma de la subordinada concesiva 'aunque yo soy moderado en las discusiones' $\mathrm{y}$, en la oración principal, la combinación del cuantificador de frecuencia baja interdum con la perífrasis 'a veces suelo enfadarme' ponen de relieve respectivamente el marco más amplio de la posibilidad de no ocurrencia y la excepcionalidad del evento.

En latín, esta compatibilidad de soleo+INFINITIVo con adverbios de frecuencia baja abre la vía a la posibilidad de la no ocurrencia. Se trata de un sentido que comporta una inferencia clara: algo sucede normalmente, sucede casi siempre, es decir, suele suceder, pero existe la posibilidad de que no suceda. Para el español, este carácter contingente de los eventos habituales ha llevado a algunos estudiosos (Giammatteo-Marcovecchio-Albano 2011: 144) a situar la construcción soler+INF en la intersección de lo aspectual y lo modal. Es decir, atendiendo a la morfología del verbo y a su construcción sintáctica, se reconoce para soler un comportamiento análogo al de los verbos modales como poder y deber, mientras que, desde el punto de vista semántico, su valor es el de un auxiliar de modo de acción (Casado-Velarde 1983). En este sentido apunta también Gómez Torrego (1999: 3377-3378), que atribuye a soler+INF un comportamiento de perífrasis modal y un valor semántico de hábito o frecuencia.

En el caso del catalán, Montserrat (en prensa) explica muy bien cómo la inferencia que lleva al valor de la posibilidad de no ocurrencia llega a rutinizarse hasta dar lugar al sentido actual de soler+INF en catalán, donde la perífrasis vehicula prototípicamente dicho valor. Efectivamente, desde una lectura moderna, enunciados como el de (16a) Mariona sol dormir en aquest llit incluyen la posibilidad de que 'a veces Mariona no duerme en esa cama', algo que no es posible inferir en los ejemplos que Montserrat aduce, en condiciones similares, del catalán anterior al XVI. Así, en el caso de su ejemplo 12, correspondiente a nuestro (16b) la cambra hon ell testis sol jaure, el contexto (que no reproducimos por cuestiones de espacio) deja claro que la habitación donde suele dormir el testigo es la suya, donde duerme siempre, sin que se implique la posibilidad de que eventualmente duerma en otro cuarto. 
(16) a. Mariona sol dormir en aquest llit (apud Montserrat, en prensa) 'Mariona suele dormir en esta cama'.

b. E encontinent muntà-sse-n en la cambra hon ell testis sol jaure (Procés Criminal 02r, 8 s. 2/XVI, apud Montserrat, en prensa) 'Y enseguida subió al cuarto donde suele yacer el testigo'.

Volviendo al latín, exactamente la misma lectura del ejemplo anterior (16b) es la que cabe aplicar en el caso de (17), donde tenemos también involucrada gente que duerme:

(17) PA. Quid facturu's? PH. Iam scies. / Anus hic solet cubare custos ianitrix. / Nomen Leaenaest, multibiba atque merobiba. (Plautus, Curculio 75-77)

'PA. ¿Qué vas a hacer? FE. Ahora lo sabrás. Aquí suele dormir una vieja encargada de la puerta. Se llama Leena, una gran bebedora y bebedora de vino puro'.

Tampoco aquí el foco está puesto en la posibilidad de que esta vieja borracha, claro precedente del personaje de la Celestina, duerma a veces en otro sitio. La vieja es ianitrix, la encargada de vigilar la puerta de la bodega y todo lleva a pensar que tiene su catre junto a la entrada de la misma.

Montserrat justifica la introducción tardía, en el siglo XVI, del valor de la no ocurrencia en catalán, y también en español, por tratarse de un valor románico que en latín no existía. Naturalmente, no podemos compartir el razonamiento, ya que hemos visto en (13) (14) y (15) ejemplos claros en latín de posibilidad de no ocurrencia a partir de la combinación de la perífrasis con adverbios de frecuencia baja. En cuanto al español, convendría revisar a la luz de dicha posibilidad, casos como el (18), donde las ocasiones en que la necesidad presta consejo parecen ser más bien pocas o, en todo caso, ni pocas ni muchas:

(18) \& porque ellos eran en poco numero dubdaron la batalla \& puestos en tanta perplexidat que non sabien que fazer. finalment la neçcessidat como suele alas uezes les dio consello. (Juan Fernández de Heredia, Grant Cronica d'Espanya, a. 1385)

No obstante, nuestro desacuerdo en este punto con la tesis de Montserrat es menor si formulamos la cuestión del siguiente modo: ni en el propio latín ni en los primeros siglos del catalán y del español, puede constatarse el valor de la posibilidad de no ocurrencia en ausencia de cuantificadores, algo que sí sucede en la lengua actual. Dicho de otro modo: en latín, la posibilidad de no ocurrencia no es un valor prototípico que tengamos codificado en la perífrasis soleo+INF, sino el resultado de una inferencia activada por la 
presencia de marcadores de frecuencia baja; lo que encontramos es una construcción gramatical que aúna la forma soleo + INF con el significado tipificador o caracterizador (vid. apartado 2). El tránsito hacia el romance marca un cambio construccional que afecta al significado de la construcción inicial y que lleva, por convencionalización de la inferencia, de un significado de posibilidad de no ocurrencia, a que dicho sentido, antes expresado por los complementos adverbiales, pase a formar parte de la semántica misma de la perífrasis soleo + INF.

\subsection{El ASPECTO CONTINUO}

De los ejemplos latinos que hemos aportado hasta aquí, parece deducirse con bastante claridad que la lectura habitual frecuentativa de la perífrasis que obtenemos cuando situamos el foco en la iteración del evento, no aparece vehiculada por la perífrasis en sí sino por los elementos cuantificadores de frecuencia con que se combina. En palabras de Havu (1997:104 ss.), y como ya hemos apuntado antes, la iteración tiene que ver con los valores aspectuales de tipo cuantificacional y se encomienda en este caso a los complementos adverbiales.

En nuestra opinión, el valor que codifica la perífrasis en ausencia de cuantificadores es únicamente un valor tipificador o caracterizador, que viene avalado además desde la vertiente léxica, por el sentido pleno del verbo soleo, cuya etimología permite relacionarlo con el pronombre personal de tercera persona y atribuirle la acepción "ser de uno, ser propio, ser normal, ser costumbre" como prototípica (vid. Cabré en este mismo volumen). Sin entrar todavía en la consideración del tipo de predicado, esta lectura caracterizadora a partir de lo que es típico o esencial es la que se obtiene en enunciados como el del ejemplo (2), donde el hábito de gastar bromas lleva a la caracterización o tipificación del personaje como un bromista, pero también es de aplicación a la vieja encargada de la puerta el ejemplo (17), cuyo cometido de portera y su afición al vino se definen esta vez en relación con la cama en la que duerme.

En el plano teórico, lo que planteamos supondría considerar la perífrasis latina soleo+INFINITIVo como variedad aspectual de manera (Klein 1982: 537), concretamente dentro del aspecto Imperfecto, pero como subvariedad, no habitual sino continua (Bertinetto 1997: 227, n.8). Como es sabido, el aspecto continuo es el típico de las situaciones no dinámicas, como los estados, pero, además, es también la modalidad no marcada del aspecto Imperfecto, es decir, la que tenemos en ausencia de lecturas habituales o progresivas (Camus 2004: 519). 
Por supuesto, no decimos que en latín no quepa hablar de otros valores. Vemos, por una parte, cómo este valor esencial y caracterizador, que define al sujeto desde su tipicidad, puede acompañarse de cuantificadores de frecuencia alta, que contribuyen a desarrollar valores frecuentativos en el ámbito cuantificacional. También, más esporádicamente, la perífrasis puede asociarse a adverbios de frecuencia baja cuando la caracterización es válida solo en relación con una pequeña cantidad de repeticiones del evento. En este segundo caso puede promoverse una lectura de la perífrasis que incluye la posibilidad de la no ocurrencia.

Así, la caracterización y los valores de soleo +INF, atendiendo a los rasgos semánticos de la construcción y a las condiciones paradigmáticas analizadas hasta aquí, podrían ilustrarse del modo siguiente:

\begin{tabular}{|c|c|c|c|c|}
\hline \multirow{2}{*}{ 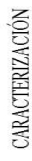 } & semántica & $\begin{array}{l}\text { hábito, costumbre o } \\
\text { tipicidad }\end{array}$ & $\begin{array}{l}\text { potencial iteración } \\
\text { del evento }\end{array}$ & $\begin{array}{l}\text { posibilidad de no } \\
\text { ocurrencia }\end{array}$ \\
\hline & sintáctica y contextual & $\begin{array}{l}\text { concurrencia de } \\
\text { sinónimos } \\
\text { contextuales }\end{array}$ & $\begin{array}{l}\text { combinación con } \\
\text { adverbios de } \\
\text { frecuencia alta }\end{array}$ & $\begin{array}{l}\text { combinación con } \\
\text { adverbios de } \\
\text { frecuencia baja }\end{array}$ \\
\hline & VALORES & aspectual continuo & aspectual habitual & modal epistémico \\
\hline
\end{tabular}

Un planteamiento como este puede resultar de aplicación, a nuestro entender, a algunos ejemplos del español antiguo que habitualmente se interpretan como pleonásticos o como alternativos a la forma simple. Se trata de casos en los que soler+INFINITIVo se da en ausencia de cuantificadores y donde se dificulta, por tanto, cualquier inferencia de valores frecuentativos o de posibilidad de no ocurrencia. Reproducimos en (19) y (20) un par de ejemplos aportados por Yllera (1980:200). No es este el lugar para entrar en el detalle, pero seguramente, al abordar la historia de la perífrasis en español, sería interesante revisar dichos usos a la luz del valor tipificador básico o de la subvariedad continua del aspecto Imperfecto que proponemos para el latín.

(19) RUB. de com $<m>$ o el cauallero amjgo fizo mucho bien al Pescador su amo con qujen el solia beujr. (Anónimo, Libro del caballero Zifar, a. 1300-1305)

(20) Et el conde tendio los ojos \& fue los poderes devissando. Et conoçio los poderes. \& fue muy ledo \& muy pagado \& dixo ala infanta esta es Castilla que me suele bessar la mano. (Anónimo, Mocedades de Rodrigo, c. 1400) 
Desechado en estos casos el valor habitual-frecuentativo, subsiste únicamente, dentro del aspecto Imperfecto, la lectura caracterizadora correspondiente al aspecto continuo: en (19) la que permite describir al caballero amigo respecto del tiempo vivido con su amo el pescador; en (20) la que, en relación con el evento representado por 'besar la mano', hace que se le reconozca a Castilla su condición de súbdita del conde.

\section{COLOCADOS LÉXICOS}

\subsection{INCOMPATIBILIDAD DE PREDICADOS}

Con independencia de que los ejemplos anteriores deban explicarse desde la habitualidad o bien que se deslicen hacia otros valores aspectuales y no aspectuales, lo cierto es que, desde el punto de vista del modo de la acción, los verbos auxiliados de la perífrasis que venimos considerando hasta el momento constituyen, por lo general, eventos iterables. Ello, visto desde la óptica actual, es consistente con el hecho de que, en principio, la habitualidad no es compatible con verbos que denotan eventos únicos, es decir, acontecimientos que suceden una sola vez, ni tampoco con predicados de tipo estativo.

Ahora bien, esta incompatibilidad construccional, que reconocemos sin demasiados inconvenientes en el español actual, no resiste con igual facilidad el análisis de los testimonios antiguos. Si en latín, tal como sostenemos, son los marcadores de frecuencia los que codifican la habitualidad y no la propia construcción soleo +INFINITIVO, consecuentemente, la naturaleza del predicado no ha de resultar relevante en la consideración de los valores de la perífrasis. Como enseguida veremos, en los ejemplos que manejamos con predicados a priori incompatibles con soleo, no descubrimos sentidos distintos a los valores caracterizadores que se imponen, en ausencia de marcadores, para predicados sin dificultades de combinación.

Por otra parte, en latín, el espectro de colocados léxicos que aparecen en la posición del infinitivo resulta más amplio que el del español o el catalán contemporáneos. Así, a diferencia de lo que acostumbra suceder en la mayoría de construcciones perifrásticas, todo lleva a pensar que en el caso de soleo+INF la evolución semántica supuso una reducción del tipo verbal al que pertenecen los infinitivos. 


\subsubsection{Eventos únicos y auxiliados perfectivos}

En (21) tenemos un ejemplo de evento único donde soler se combina con los predicados 'nacer' y 'morir'. Tertuliano, para denostar la naturaleza de los dioses paganos, ofrece una relación de situaciones que permite equipararlos a los hombres cristianos.

(21) In metalla damnamur: inde censentur dei uestri. In insulas relegamur: solet et in insula aliqui deus uester aut nasci aut mori. (Tertullianus, Apologeticum 12).

'Somos condenados a las minas: de ahí se consideran vuestros dioses. Se nos relega a las islas: también algún dios vuestro suele o nacer o morir en una isla'.

Los predicados 'nacer' y 'morir' son logros y, por tanto, eventos télicos, pero además suponen eventos únicos, lo que dificulta la lectura habitual. Se podría pensar que la presencia del indefinido aliqui denota, de hecho, un sujeto plural y que, en consecuencia, los eventos 'nacer' y 'morir' pueden considerarse iterados en la medida en que se predican de más de uno de los componentes de este sujeto, es decir, de dos o más dioses paganos. Pero ello tampoco garantizaría la lectura habitual puesto que, aun siendo plural, no estamos ante un sujeto genérico. En definitiva, el valor que aflora en este caso no es otro, en nuestra opinión, que el aspectual continuo, adecuado para señalar los predicados 'nacer o morir en una isla' como característica definitoria de alguno de los dioses paganos.

Creemos que este sería también un argumento válido para explicar la presencia de soler+INF en algunos ejemplos del español del XIII que Yllera (1980:199-200) considera usos de la perífrasis equivalentes a la forma simple, dado que en ellos el carácter perfectivo del auxiliado impide la lectura frecuentativa. Tal es el caso del que reproducimos en (22).

(22) Tanto buen amigo vos me soliádes ganare / por vestra amor arriba muychos me solián amare; / pues uos sodes muerto, sobrino, buscar me an todo male. (Anónimo, Cantar de Roncesvalles, a. 1225-1250)

Pese a que en ejemplos como este siempre podrán invocarse razones métricas (Uría 1978), en nuestra opinión, lo que diferencia el uso de la forma simple del de la perifrástica es precisamente que, con esta última, se evidencia y se formaliza la atribución al sujeto de las características o propiedades expresadas por el predicado: Roldán tenía la cualidad de granjearse amistades provechosas para su tío Carlomagno y, de resultas de ello, se podía predicar de muchos individuos que amaban a este último gracias al amor que le tenían al primero. 


\subsubsection{Predicados estativos y pasivos}

Desde el punto de vista de la compatibilidad con el modo de acción, se sostiene comúnmente que la perífrasis actual es también refractaria a los verbos estativos (García Fernández 2006: s.v. "soler"). Tampoco es esta una restricción que pueda observarse en latín.

En los ejemplos (23) y (24) tenemos, concretamente, verbos de estado, es decir, los que corresponden en rigor a situaciones no dinámicas. En (23) hemos retomado el ejemplo plautino de la vieja portera de la bodega que bebe tanto que se la llega a comparar con un lagar donde 'suele estar, suele guardarse' el buen vino, esto es, el vino de Quíos. De este vino no se predica que se guarde en la bodega ni muchas veces ni pocas, sino que se señala lo que constituye una propiedad, una característica tipificadora del mismo.

(23) PH. Nomen Leaenaest, multibiba atque merobiba. PA. Quasi tu lagoenam dicas, ubi uinum Chium solet esse. (Plautus, Curculio 77-78) 'F. Se llama Leena, una gran bebedora y bebedora de vino puro. P. Vamos, como si dijéramos una bodega, donde suele estar el vino de Quíos'.

En (24), el polígrafo Varrón, en su tratado sobre la lengua latina, discute la etimología del término scrup(i)peda, 'el que camina con dificultad' y recoge la propuesta de Juvencio para quien el término procede de un gusanillo peludo que se encuentra en el follaje.

(24) scruppedam Aurelius scribit ab scauripeda; Iunentius comicus dicebat a uermiculo piloso, qui solet esse in fronde cum multis pedibus; Valerius a pede ac scrupea. (Varro, De lingua Latina 7, 3,65)

'Aurelio escribe que scruppeda procede de scauripeda 'de pies contrahechos'; el comediógrafo Juvencio decía que (procede) de un gusanillo peludo, que suele haber en el follaje, con muchos pies'.

En el español actual, la presencia de la perífrasis en casos como estos se ha puesto en relación con la lectura genérica del enunciado, dado que el carácter genérico del sujeto 'vino' y 'gusanillo' no permite la lectura individual. (Vatrican 2015: 108-110).

En la misma línea, Camus (2011: 142-157), entre los casos excepcionales de combinación de soler con verbos de estado que se dan en el español del País Vasco, señala la compatibilidad con predicados estativos de ocurrencia múltiple, esto es, casos en que la selección de un sujeto en plural garantiza la multiplicidad. 
(25) En cualquier caso, que nadie se olvide del cortavientos en la mochila, porque las zonas más altas suelen ser bastante ventosas por estas fechas. (Diario Vasco, 22-X-2010, apud Camus 2011)

Con todo, para el empleo de soler con verbos estativos, tanto si la combinación es efectivamente propia del español moderno o solo de algunas variedades, se hace necesario tomar también en cuenta algunos usos del español antiguo.

(26) Et sennor los de nuestra tierra non suelen seer ombres salidizos nin sabemos mesurar las tierras quan grandes son: nin quan aluenle son las unas de las otras. (Alfonso X, General Estoria. Segunda parte, c. 1275)

Yllera (1980:200) considera estos usos de la perífrasis como casos pleonásticos donde se destaca una acción durativa y no un hecho habitual. Sin embargo, Montserrat (en prensa) ha señalado con mucho acierto que tacharlos de pleonásticos es hacer una lectura desde los valores actuales de la perífrasis: en realidad lo que subyace en estos casos es un valor, propio de la lengua medieval, que se obtiene como resultado de inferencias asociadas motivadas por el conocimiento compartido entre hablante y oyente. Esto es, de soler+INF el oyente infiere en estos casos que el evento sucede siempre.

Este valor se remonta al latín y, en nuestra opinión, no difiere del valor caracterizador básico que venimos señalando como valor primario de soleo ${ }^{+}$ INF incluso cuando no se dan teóricas incompatibilidades con el tipo de predicado.

En el ejemplo (27), Pirgopolinices, el soldado fanfarrón, da órdenes de que limpien su escudo para que quede resplandeciente, 'más resplandeciente -puntualiza- de lo que lo suelen ser los rayos del sol cuando el día está despejado'.

(27) PY. Curate ut splendor meo sit clipeo clarior / quam solis radii esse olim quom sudumst solent. (Plautus, Miles gloriosus 1-2)

'PI. Procurad que la brillantez de mi escudo sea más resplandeciente de lo que suelen serlo los rayos del sol cuando está sereno'.

Dado que el resplandor de los rayos del sol, asociado a los días claros, está garantizado, lo que inferimos de la perífrasis en ejemplos de este tipo no es, evidentemente, la habitualidad entendida como frecuencia sino la cualidad, la propiedad esencial que caracteriza al sujeto en las circunstancias que se aducen. 
En latín, hemos observado un comportamiento asimilable al de soleo con predicados estativos en las ocasiones en que encontramos el infinitivo auxiliado en voz pasiva, como en (28) y (29).

(28) At ego aio id fieri in Graecia et Carthagini / Et hic in nostra terra, in Apulia: / maioreque opere ibi seruiles nuptiae / quam liberales etiam curari solent. (Plautus, Casina 68-71)

'Pero yo os aseguro que eso sucede en Grecia y en Cartago, y aquí mismo, en nuestra tierra, en Apulia. En estos sitios las bodas de esclavos suelen ser celebradas / se suelen celebrar incluso con más solemnidad que las bodas de hombres libres'.

(29) His enim diebus rogationes publicae caelebrabantur, quae ante sanctum dominicae ascensiones diem agi solent. (Gregorius Turonensis, Historiarum libri $X, 9,6$ )

'En esos días, efectivamente, se celebraban las rogativas públicas, que suelen ser llevadas / llevarse a cabo antes del día de la ascensión de nuestro Señor'.

Estos predicados están también presentes en español (30) y en catalán (31) antiguos, si bien hay que notar que en estas lenguas es el auxiliar soler el que, mediante el pronombre 'se', asume las características medio-pasivas del predicado.

(30) E los sabios antiguos dizen que ssyson es el Rio a que llaman arrlo al que dizen en araujgo alluno \& en ebrayco njlos. E dizen que en el tienpo antiguo se solje somjr $\&$ perder so la tierra \& fazia toda la tierra tremedal de gujsa que non podie njnguno andar sobrella. (Anónimo, Libro del caballero Zifar, a. 1300-1305, apud Yllera 1980)

(31) car les coses noves solen més plaure e ab més sforç executar que les molt vistes, e lo que hom no té se sol ab major afecció desitjar que lo que hom posehex, e neguna cosa és tan delitosa que per lonch ús no torne enujosa. (Tirant 1080, 8 2/XV, apud Montserrat, en prensa) 'pues las cosas nuevas suelen agradar más y ejecutarse con mayor empeño que las que están muy vistas, y lo que uno no tiene se suele desear con mayor anhelo que lo que uno posee, y no hay nada que con el uso prolongado no se vuelva enojoso'.

\subsubsection{Verbos actitudinales}

Un tipo de predicados muy interesantes cuando se combinan con soler es el de los llamados actitudinales, predicados que se refieren a actividades 
propias desarrolladas por un profesional. Bertinetto (2004: 307-312) los sitúa en la intersección entre los habituales y los estativos permanentes, dado que son una subclase de los habituales, pero su comportamiento es el de los estativos. Para este estudioso, los actitudinales expresan aspecto habitual -de hecho, él los llama "habituales actitudinales"-, pero presentan una forma particular de habitualidad: se trata de predicados que se vuelven contextualmente estativos permanentes, es decir, predicados donde la aparición regular de un cierto evento se torna propiedad permanente de un individuo o conjunto de individuos. Formalmente, los actitudinales son el resultado de lo que Lenci (1995: 143-158) considera un tipo particular de "coerción" que impone carácter estativo a su naturaleza eventiva básica.

En latín, podemos ilustrar la combinación del auxiliar soleo con predicados actitudinales con los ejemplos (32), (33) y (34). El cocinero de (32) es calificado de nundinale porque se lo compara a un mercadillo romano, que realiza su actividad cada ocho días. Pero es necesario ver que, si no tuviéramos esa definición previa y nos quedáramos solo con la parte justificativa, es decir, "suele venir a cocinar una vez cada ocho días", de inmediato llevaríamos la perífrasis al terreno de la habitualidad y, es más, inferiríamos la frecuencia a partir de la expresión distributiva in nonum diem. (cf. Petronius, Satyrica 46: feriatis diebus solet domum venire "suele venir a casa los festivos")

(32) Cocus ille nundinalest, in nonum diem solet ire coctum. (Plautus, Aulularia 324)

'Ese es un cocinero de mercadillo: suele venir a cocinar una vez cada ocho días'.

En (33), la perífrasis sirve para predicar de un artesano el trabajo de redondeo que realiza al tornear.

(33) sed cum omne caelum ita reuoluatur ut sphaera, eam tamen radicibus oportet teneri, quas diuina machinatio uerticibus adfixit, ut in tornando artifex solet forcipe materiam comprehensam reciproco uolumine rotundare. (Apuleius, De mundo 1)

'Pero pese a que el cielo entero gire como una esfera, es preciso sin embargo sostenerlo con los pivotes que un mecanismo divino ha ajustado a los vértices, como el artesano, al tornear, suele redondear con las pinzas la pieza contenida con un movimiento circular en un sentido y en otro'.

Y en (34), la utilización de soleo+INFINITIVo pone de relieve la falta de oficio de Crísida y, en cambio su capacidad de observación psicológica. 
(34) Vides me: nec auguria noui nec mathematicorum caelum curaresoleo, ex uultibus tamen hominum mores colligo, et cum spatiantem uidi, quid cogitet scio. (Petronius, Satyrica 126, 3)

'Ya me ves: ni entiendo de augurios ni suelo observar el cielo de los astrónomos, pero de los rostros de los hombres deduzco sus costumbres y cuando a uno lo he visto moverse, sé lo que piensa'.

En los ejemplos anteriores, la función de los llamados actitudinales es, como vemos, la de predicar actividades que pasan a caracterizar a un determinado sujeto. Ello hace que el valor de soleo+INFINITIVo no sea distinto del que hemos analizado al principio, en los ejemplos (2) y (3), a propósito del personaje caracterizado por su afición a las bromas. De hecho, la distancia entre lo habitual, entendido como simple hábito, y lo actitudinal es muy poca. Tanto en un caso como en el otro, lo relevante y lo común a ambos es la atribución de una propiedad o de una característica a un individuo o entidad. La única diferencia que puede señalarse es que dicha propiedad es permanente en los actitudinales, mientras que es contingente en el caso de los habituales.

Considerados bajo esta óptica, pueden explicarse algunos usos de la perífrasis del español medieval que, como señala Yllera (1980: 200) con razón, pese a parecer pleonásticos, responden en realidad a un empleo más amplio del verbo soler en la lengua antigua.

(35) E esta estoria de los quatro Rios del parayso fue aqui puesta por que sepan que el jnperio de trigida tomo nonbre deste Rio trigris. E es vna grand partida del jnperio por allj por do solia correr \& la otra partida do se buelue con el rrio de eufrates llega fasta la mar. (Anónimo, Libro del caballero Zifar, a. 1300-1305)

\subsection{LA SELECCIÓN DEL SUJETO}

Se trate de predicados habituales, estativos o actitudinales, la lectura caracterizadora de soleo+INFINITIVo, común a todos ellos, contribuye a la aparición de la perífrasis en un tipo de enunciados próximos a las sentencias o a los proverbios, cosa bastante lógica por la función definitoria de la mayoría de ellos. Por lo común, el núcleo verbal es un presente de tipo general o gnómico y, por otra parte, el tipo de sujeto impone normalmente una lectura genérica, algo que tampoco resulta extraño dado que este tipo de enunciados son una expresión de la generalización. Así, en el ejemplo (36) se obtiene la lectura genérica a partir del valor generalizador de la oración 
de relativo sustantivada, y en (37) promueve esa misma lectura la selección del abstracto aequalitas como sujeto.

(36) at quid interest inter periurum et mendacem? qui mentiri solet, peierare consuevuit. (Cicero, Pro Roscio Gallo comoedo 45)

¿QQué diferencia hay entre un perjuro y un mentiroso? Quien suele mentir, acostumbra perjurar'.

(37) Aut numquid ipso uos $c<$ ol $>$ legio offendimus? solet aequalitas aemulationis materiam subministrare: sic figulus figulo, faber fabro inuidet! (Tertullianus, Ad nationes 1, 20)

¿Acaso os ofendemos con esta afinidad compartida? La igualdad suele dar pábulo a la envidia: así, un alfarero envidia a un alfarero, un artesano a un artesano'.

Esta selección de nombres abstractos como sujeto también se da en algunos ejemplos del español de los primeros siglos y se corresponde claramente, como puede verse en (38), con el valor caracterizador de la perífrasis que venimos destacando como sentido básico de la misma. Curiosamente, a partir del siglo XV, esa misma lectura caracterizadora y, aquí, generalizadora, se concentra en la forma simple del verbo, tal como encontramos reproducido en (39).

(38) Commo dize el prouerbio, que suele retrayer, / que la copdiçia mala saco suele ronper, / fiço la promesa a muchos falleçer, /que lo querrìan de grado ho matar o prender. (Libro de Apolonio, c.1240)

(39) Cobdiçia mala saco rompe. (Marqués de Santillana, Refranes que dizen las viejas tras el fuego, a. 1454)

\subsection{VALOR LÉXICO Y ASOCIACIÓN SINTÁCTICA}

Además de cuanto ya hemos observado, la utilización de la perífrasis soleo+INFINITIVo para atribuir una determinada característica a un sujeto con relación a un hábito se corresponde con su presencia mayoritaria en el seno de estructuras sintácticas empleadas en la definición, la descripción o la caracterización de un nombre. Efectivamente, soleo+INFINITIVo constituye con frecuencia el predicado verbal de oraciones de relativo (por ejemplo, un nutrido grupo de los ejemplos analizados anteriormente). Ello resulta lógico y perfectamente adecuado a la caracterización semántica de la construcción, dado que una gran parte de las oraciones de relativo, por su carácter asertivo y por su capacidad de incidencia en el antecedente, sirve para presentar 
eventos, estados y actitudes característicos de este. Así, en el ejemplo (40) la oración relativa, de carácter explicativo, define a Mercurio a partir de su habitual actividad de conducir las almas. Por su parte, el ejemplo (41), señala, mediante la oración adjetiva, los prodigios que acompañaron el nacimiento de Teodorico II, rey de Borgoña, como representativos y característicos de calamidades varias, entre ellas, la muerte de un rey.

(40) Mercurius enim, qui animas ducere et reducere solet, suis beneficiis reddidit mihi quod manus irata praeciderat, ut scias me gratiosiorem esse quam Protesilaum aut quemquam alium antiquorum. (Petronius, Satyrica 140, 12)

'Mercurio, que suele conducir las almas de ida y de vuelta, con su gracia me ha devuelto lo que una mano airada había cortado, para que veas que estoy más dotado que Protesilao y que cualquier otro de los antiguos'.

(41) Et multa alia signa apparuerunt, quae aut regis obitum adnunciare solent aut regiones excidium. (Gregorius Turonensis, Historiarum libri X 9, 5)

' $Y$ aparecieron otras muchas señales, que suelen anunciar, o la muerte de un rey, o calamidades para los pueblos'.

Con mayor frecuencia si cabe, encontramos la perífrasis utilizada en oraciones modales o comparativas. También aquí se trata de estructuras sintácticas que se corresponden perfectamente con la semántica de soleo+INF, ya que las comparativas, como las oraciones de relativo, lo que hacen es expandir el significado de un núcleo antecedente. De hecho, la comparación o el símil supone una forma de generalización controlada o parcial que es naturalmente afín al valor continuo de la perífrasis. En el siguiente ejemplo de la General Estoria (42), el sentido del enunciado 'Dios acompañó a su pueblo' se expande, mediante la comparación, a otras situaciones en las que un padre (genérico) guía en el camino a su hijo pequeño. Conviene observar que dicha expansión se produce, además, con el apoyo de la caracterización que introduce la perífrasis a propósito de ese mismo padre.

(42) E assí [Dios] vos aduxo fasta que viniestes a este logar como suele ell omne traer por la carrera su fijuelo pequeño. (Alfonso X, General Estoria. Primera parte, c. 1275)

En nuestra opinión, estos casos constituyen un argumento más para sostener que el valor básico de la perífrasis no es el habitual-frecuentativo -codificado en todo caso por los marcadores-, sino el que la sitúa en el ámbito del aspecto continuo, como modalidad no marcada del aspecto Imperfecto. 
Así, en el ejemplo (43), que retomamos aquí a partir del anterior (13), encontramos soler combinado con una expresión de frecuencia baja de la que podemos inferir la posibilidad de la no ocurrencia, pero ello no supone impedimento para que la perífrasis, en el seno de la oración comparativa, contribuya a la caracterización de la neçcessidat de acuerdo con su actuación en circunstancias o microeventos determinados.

(43) \& porque ellos eran en poco numero dubdaron la batalla \& puestos en tanta perplexidat que non sabien que fazer. finalment la neçcessidat como suele alas uezes les dio consello. (Juan Fernández de Heredia, Grant Cronica d'Espanya, a.1385)

En latín, como en español, son varios los nexos modales que documentamos para estos casos: en especial ut (ejemplo 44) y sicut (45); pero también elementos de comparación relativos (ejemplos 46 y 47).

(44) sed, ut solebat C. Lucilius saepe dicere, [...] sic sentio neminem esse in oratorum numero habendum, qui non sit omnibus iis artibus, quae sunt libero dignae, perpolitus. (Cicero, De oratore 1, 72)

'Pero, como solía decir Gayo Lucilio a menudo, [...] soy del parecer de que nadie que no se haya refinado en esas artes que son dignas de un hombre libre ha de ser tenido por un orador'.

(45) licet iste dicat emisse, sicuti solet dicere, credite hoc mihi iudices: nulla umquam ciuitas tota Asia et Graecia signum ullum, tabulam pictam $<$ ullam $>$ ullum denique ornamentum urbis sua uoluntate cuiquam uendidit. (Cicero, In Verrem orationes sex, actio secunda 4, 133) 'Ya puede decir ese que lo compró, tal como suele decir; creedme, jueces, nunca ninguna comunidad, en toda Asia y Grecia, vendió a nadie por propia voluntad estatua alguna, cuadro alguno ni, en fin, ornamento alguno de la ciudad'.

(46) quam ob rem etiam sessiones quaedam et flexi fractique motus, quales proteruorum hominum aut mollium esse solent, contra naturam sunt. (Cicero, De finibus 5, 12)

'Por eso, también ciertos modos de sentarse y los movimientos lánguidos y lascivos, cuales suelen ser los de los hombres corrompidos o afeminados, van en contra de la naturaleza'.

(47) per fidem, miserere, quemadmodum quidem soles'. (Petronius, Satyrica 114, 5)

'Por piedad, compadécete de la forma en que efectivamente sueles'. 
A propósito de este último ejemplo (47) no podemos dejar de señalar que es en las oraciones de relativo y en las estructuras modales o comparativas donde hallamos con mayor frecuencia, en latín y en español, casos de anáfora cero, que supone la elipsis del infinitivo de la perífrasis (Manfredini 2016: 262-276). Sin descartar la posibilidad de que se trate de usos de soler como verbo pleno (Olbertz 1998: 126-128), ello guarda sin duda relación con el hecho antes mencionado de que ambas estructuras se utilizan como extensión de un concepto o de una información previa, que puede omitirse sin dificultad cuando se retoma, mediante la perífrasis, con vistas a su generalización.

Los ejemplos de soleo/soler + INFINITIVo que nos han servido de base en este apartado son aquellos en los que el tipo de predicado no permite hablar de iteración del evento y que, en consecuencia, son a priori incompatibles con la habitualidad entendida como frecuencia. Hemos visto cómo en todos ellos parece imponerse la misma lectura caracterizadora que hemos señalado, en el primer apartado, como propia de enunciados que sí son susceptibles de iteración pero que, por defecto, no encontramos acompañados de marcadores de frecuencia. Unos y otros casos apuntan, pues, en la línea del aspecto continuo, que en nuestra opinión constituye el valor prototípico de la perífrasis en latín y que puede también reivindicarse para muchos de los ejemplos del español medieval que se han venido considerando pleonásticos.

\section{TIEMPO Y ASPECTO}

\subsection{EL IMPERFECTO}

Los testimonios del latín que documentan la perífrasis con el auxiliar soleo conjugado en pretérito imperfecto no difieren, en su lectura, del comportamiento y de los valores de la perífrasis en los primeros textos romances. Así, el uso de soleo en tiempo imperfecto es naturalmente compatible y convive, de hecho, con los valores de los que venimos ocupándonos.

En el ejemplo (48) tenemos un predicado actitudinal que atribuye al sujeto una determinada propiedad, lo cual confiere a la perífrasis un valor caracterizador. Este valor es compatible con el valor epistémico de la no ocurrencia, no solo porque está claro que el personaje en cuestión es un feriante y no un abogado, sino porque el marcador temporal aliquando deja patente las pocas ocasiones en que el feriante se dedicaba a los pleitos. 
En (49), en cambio, el complemento de tiempo plural 'por las tardes', y la precisión subsiguiente, también plural, apuntan a la frecuencia con que, en relación con los microeventos expresados, las sobras de los banquetes acababan en la habitación.

(48) nescio quis ex cocionibus, caluus, tuberosissimae frontis, qui solebat aliquando etiam causas agere, inuaserat pallium exhibiturumque crastino die affirmabat. (Petronius, Satyrica 15,4)

'No sé quién de los feriantes, uno calvo, con la frente llena de granos, que de vez en cuando solía también llevar pleitos, se había quedado el manto y decía que lo traería al día siguiente'.

(49) nam uespera post opiparas cenas earumque splendidissimos apparatus multas numero partes in cellulam suam mei solebant reportare domini. (Apuleius, Metamorphoses 10, 13)

'Por las tardes, después de las suculentas cenas y de sus espléndidas magnificencias, mis amos solían llevarse a su habitación una buena cantidad de sobras'.

Ahora bien, además de presentar los valores ya señalados, en todos estos casos el imperfecto presenta el acontecimiento expresado por el verbo auxiliado confinado en un pasado que no puede extenderse en modo alguno hasta el presente, de modo que la costumbre, el hábito o la caracterización que se predica del sujeto solo es válida en el ámbito del pasado. Ello puede explicarse como un proceso de subjetivización que provoca que la expresión de lo habitual deje de asociarse a la perífrasis (Squartini 2010: 544). En estas ocasiones, la función de soleo + INF en imperfecto no es tanto la de referir un determinado estado de cosas en el pasado cuanto la de contrastarlo con el presente.

Para el español, Yllera (1980: 200) explica estos casos como expresión de una acción reiterada o durativa que ha cesado en el presente. Se compara - dice- la situación presente con la situación usual en el pasado. El contraste entre pasado y presente resulta manifiesto en el ejemplo (50) de Calila e Dimna. La lectura que resulta aquí de la perífrasis se acompasa con el relato de los hechos y nos lleva del hábito característico en un pasado donde las truchas constituyen el sustento de una vieja garza, hasta el confinamiento de ese hábito, debido a que la presencia de unos pescadores viene a mermar las posibilidades de subsistencia del animal.

(50) Dixo ella:-Más mal que bien, yo solía bevir de las truchas, et acaesçió oy que vi dos pescadores venir a este nuestro lugar, et dixo el uno al 
otro: - ¿Por qué non echamos alguna vez la red aquestas truchas que son en aqueste lugar? (Anónimo. Calila e Dimna, a. 1251)

Son numerosas las evidencias que tenemos en latín de dicho contraste. En el pasaje de Los prisioneros de Plauto (51), la acción está claramente confinada en el pasado con ante. El propio contexto y los tiempos verbales ponen en evidencia la contraposición entre el pasado, cuando Ergásilo se ganaba la vida con sus chistes, y el presente cuando nadie le ríe las gracias y, por supuesto, no le recompensa ni siquiera el mejor de sus chistes. En el siguiente testimonio (52), también plautino, la precisión temporal es todavía mayor: el evento representado por el saludo que Alcmena dispensaba a su marido Anfitrión cuando este llegaba a casa, queda confinado en el pasado con el uso en imperfecto de soleo; pero, además, del marcador temporal antidhac 'antes de ahora' inferimos automáticamente la no extensión del evento en el presente deíctico. Por ello, el valor de costumbre o hábito que asociamos a la perífrasis en tiempo presente se desplaza aquí hasta un nuevo valor tempo-aspectual de confinamiento en el pasado.

(51) Dico unum ridiculum dictum de dictis melioribus, / quibus solebam menstrualis epulas anteadipiscier: / nemo ridet. (Plautus, Captiui 482)

'Digo uno de mis mejores chistes, con los que antes solía conseguir cenas para un mes: nadie se ríe'.

(52) AL. Qui istuc in mente $<\mathrm{m}>$ st tibi ex me, mi uir, percontarier? / AM. Quia salutare aduenientem me solebas antidhac, / appellare itidem ut pudicae suos uiros quae sunt solent. (Plautus, Amphitruo 711) 'AL. ¿Cómo se te ocurre preguntarme eso, marido mío? AN. Porque hasta ahora solías saludarme a mi llegada y darme la bienvenida como suelen hacer con sus maridos las que son virtuosas'.

\subsection{EL PERFECTO Y LOS LÍMITES}

Como antes hemos señalalado, en los casos en que la perífrasis se ancla en el pasado, la particularidad del latín con respecto al español estriba no tanto en los usos y valores del pasado imperfecto, cuanto en el hecho de que el auxiliar soleo puede conjugarse en tiempo perfecto solitus sum y asumir valores tanto perfectivos (solo con límite izquierdo) como aorísticos (con doble límite). En otro lugar (Artigas-Cabré, en prensa) nos ocuparemos con mayor detalle de la cuestión. Aquí debemos limitarnos a plantearla someramente. 
En el ejemplo (53), tenemos solitus es, con un auxiliado sobreentendido (puede ser dare operam o bien un proverbo de tipo facere) que coexiste con el momento presente de la intervención del personaje. Este perfecto tiene valor resultativo y, dada la extensión del evento hasta el presente, la perífrasis no puede estar codificando el confinamiento en el pasado de dicho evento.

(53) cape sis uirtutem animo et corde expelle desidiam tuo: / in foro operam amicis da, ne in lecto amicae, ut solitus es. (Plautus, Trinummus 651) 'Vamos, cobra valor dentro de ti y expulsa de tu corazón la desidia: en el foro, echa una mano a los amigos, y no en la cama a tu amiga, como acostumbras'.

En cambio, en (54), donde tenemos la misma forma de pasado solitus es, los eventos sobre los que el viejo Simón interroga al proxeneta Balión, se hallan claramente delimitados por la derecha, esto es, en su final. Es decisiva la presencia del predicativo puer 'de niño', que excluye cualquier extensión del evento en el presente. Por otra parte, aquí la perífrasis no sirve para establecer el tipo de contraste que hemos visto en el caso del tiempo imperfecto, sino solo para confinar el evento en el pasado sin que de ahí se nos invite a inferir otros valores codificados por la propia perífrasis. Ello no quiere decir que no los podamos inferir, tal como señalábamos al principio, de un contexto en el que actúen marcadores de frecuencia u otros elementos cuantificacionales. De hecho, en este mismo ejemplo (54) el auxiliado cubitare es, por su morfología, un verbo frecuentativo, del que inferimos el valor frecuentativo de la perífrasis en su conjunto (de ahí la traducción que hemos propuesto).

(54) BA. Quid ais? tune etiam cubitare solitu's in cunis puer? / SI. Scilicet. BA. Etiamne facere solitus es — scin quid loquar? / SI. Scilicet solitum esse. (Plautus, Pseudolus 1177)

'BA. ¿Y qué me dices? Tú, de niño, ¿te dedicaste a meterte en cama ajena? / SI. Claro. BA. ¿Y también te dedicaste a hacer ... ya sabes de qué hablo? / SI. Claro que lo hice'.

El pasaje del Pro Murena de Cicerón que reproducimos en (55) resulta muy interesante para reseguir el juego de inferencias que asociamos a la perífrasis por invitación del contexto mismo. La mera consideración de la secuencia tibi solitus sum dicere no bastaría para inferir otro valor más que el de describir la postura de Cicerón con respecto a la candidatura de Servio y el de confinar en un pasado definido sus advertencias al respecto. Ahora bien, en el contexto general de este pasaje, con un claro clímax ascendente, la lectura que se impone es, sin lugar a dudas, la habitual frecuentativa que asociamos a la escalaridad con que se presentan los eventos previos. 
(55) Et quoniam ostendi, iudices, parem dignitatem ad consulatus petitionem, disparem fortunam prouincialium negotiorum in Murena atque in Sulpicio fuisse, dicam iam apertius in quo meus necessarius fuerit inferior, Seruius, et ea dicam uobis audientibus amisso iam tempore quae ipsi soli re integra saepe dixi. Petere consulatum nescire te, Serui, persaepe tibi dixi; et in eis rebus ipsis quas te magno et forti animo et agere et dicere uidebam tibi solitus sum dicere magis te fortem accusatorem mihi uideri quam sapientem candidatum. Primum accusandi terrores et minae quibus tu cotidie uti solebas sunt fortis uiri, sed et populi opinionem a spe adipiscendi auertunt et amicorum studia debilitant. (Cicero, Pro Murena 43)

'Y puesto que he demostrado, jueces, que en Murena y Sulpicio fueron semejantes los méritos para pretender el consulado, pero distinta la suerte en orden a sus funciones públicas, voy a decir ya con mayor claridad en qué fue inferior mi íntimo amigo Servio, y expondré ante vosotros, ahora que ya se ha pasado la sazón, lo que le dije a solas a menudo, cuando todavía era tiempo. Te dije muy a menudo, Servio, que no sabías pretender el consulado. Y aun en aquello mismo que yo te veía hacer y decir con valentía y firmeza, con frecuencia llegué a decirte que más me parecías un acusador enérgico que un hábil candidato. Ante todo, las intimidaciones y amenazas de acusación, que tú solías emplear a diario, te acreditan de enérgico, pero disminuyen la creencia general en tu esperanza de obtener el cargo, y entibian el entusiasmo de tus amigos'.

También en estas ocasiones en las que tenemos el auxiliar en tiempo perfecto, y como ya hemos observado en ejemplos anteriores, si la habitualidad no viene marcada por elementos (morfológicos, léxicos o sintácticos) que expresen la frecuencia, el valor que subsiste es únicamente el caracterizador del sujeto. Así, en el ejemplo (56), un Cicerón enfadado con su amigo Ático porque este no ha respetado el periodo de tiempo necesario para la revisión de una obra suya, con lo cual circulan copias sin el placet del autor, compara el proceder de Ático con el de Hermodoro, un personaje qui Platonis libros solitus est divulgare ‘que se dedicó a divulgar los diálogos de Platón' sin el consentimiento del filósofo. La atribución de esta actividad al sujeto sirve para caracterizarlo de igual modo a como lo haría un predicado actitudinal.

(56) Dic mihi, placetne tibi primum edere iniussu meo? hoc ne Hermodorus quidem faciebat, is qui Platonis libros solitus est diuulgare. (Cicero, Epistulae ad Atticum, 13.21a., 1,1)

'Díme, ¿te parece bien publicar sin orden mía? Esto no lo hacía ni siquiera Hermodoro, ese que se dedicó a difundir los libros de Platón'. 
Lo relevante para los usos de solitus sum+INF es que el valor caracterizador no puede entenderse aquí en el marco del aspecto Imperfecto. El carácter aorístico del auxiliar presenta la perífrasis en una situación de confinamiento en el pasado que no permite la prosecución del macroevento más allá del límite derecho del intervalo de referencia. Ello, con independencia de que los microeventos sí puedan tener una valencia aspectual, impide interpretar la perífrasis desde la habitualidad, cosa perfectamente posible con las formas de pasado imperfectivo.

Este uso particular de la perífrasis en latín, ajeno a las lenguas romances, tiene en cambio muchos puntos de coincidencia con el de la construcción used to + INF del inglés. Bertinetto (1997: 215-222), que ha estudiado la perífrasis inglesa estableciendo las diferencias formales y de comportamiento con respecto a las correspondientes italianas, afirma rotundamente que, pese a la denominación tradicional, en la construcción inglesa, donde la iteración del evento no es un dato necesario, el valor habitual no constituye el sentido básico de la perífrasis. Por el contrario, esta se sitúa muy próxima a los valores que se asocian al aspecto continuo, a pesar de la situación de conflicto que Bertinetto mismo reconoce con respecto a los rasgos definitorios de esta variedad aspectual, tradicionalmente considerada como subvariedad únicamente del aspecto Imperfecto. Mientras que la perífrasis inglesa, en el plano temporal, se sitúa de lleno en el valor de confinamiento en el pasado, en cuanto a las propiedades aspectuales, la no trasposición del límite derecho del intervalo de referencia comporta una peculiar mezcla de propiedades aspectuales imperfectivas y perfectivas.

La tesis de Bertinetto en este punto puede suscribirse y, salvando las diferencias, aplicarse a la discriminación del par solebam / solitus sum del latín (Artigas-Cabré, en prensa). Es más, en nuestra opinión, constituye un argumento sólido en favor de la lectura caracterizadora correspondiente al aspecto continuo que hemos venido defendiendo para soleo+INF a lo largo de estas páginas.

\section{RECAPITULACIÓN Y CONCLUSIONES}

Existen dificultades para sostener que el valor originario de la construcción latina soleo + INF sea el habitual, dado que el requisito de evento iterable que promueve la habitualidad no siempre se da y, en ocasiones, ni siquiera se plantea como condición necesaria. 
Las veces en que soleo se conjuga en tiempo presente o imperfecto, la incompatibilidad de la construcción con el aspecto habitual se manifiesta especialmente en la combinación de soleo con predicados estativos, ya sean propiamente de estado o actitudinales (ejemplo 23, aquí citado como 57). Pero también revisten dificultades para la interpretación habitual los casos en que la perífrasis no se acompaña de marcas explícitas de habitualidad o de frecuencia (2, aquí 58).

(57) Quasi tu lagoenam dicas, ubi uinum Chium solet esse. (Plautus, Curculio 78)

'Como si dijéramos una bodega, donde suele estar el vino de Quíos'.

(58) Soleo hercle ego garrire nugas. (Plautus, Aulularia 30)

'Por Hércules, yo suelo decir bobadas'.

En estos casos se impone una lectura tipificadora o caracterizadora como resultado de la atribución al sujeto de una determinada situación o actividad. Dicha caracterización no se corresponde con el aspecto habitual sino con el continuo, la modalidad no marcada del aspecto Imperfecto y la que cabe situar, a nuestro entender, en el origen de otros valores en latín. También el aspecto continuo es válido para explicar muchos de los usos de soler+INF tradicionalmente considerados pleonásticos en el español medieval.

Por otra parte, en latín, soleo puede aparecer conjugado en tiempo perfecto con valor aorístico. En dichas condiciones, la construcción, como sucede con used to en inglés, impone la no trasposición del límite derecho, lo cual resulta incompatible con el aspecto Imperfecto (o inconcluso, García Fernández 2004: 31ss.). Aun así, en el ámbito del aspecto Perfecto o concluido, subsiste la lectura tipificadora o caracterizadora, muy próxima todavía al aspecto continuo, tal como puede observarse en el ejemplo (56), que aquí recogemos como (59).

(59) hoc ne Hermodorus quidem faciebat, is qui Platonis libros solitus est diuulgare. (Cicero, Epistulae ad Atticum, 13.21a., 1,1)

'Esto no lo hacía ni siquiera Hermodoro, ese que se dedicó a difundir los libros de Platón'.

En definitiva, o bien para el latín y el español antiguo -a diferencia de la lengua moderna- es posible hablar de aspecto continuo también como subvariedad del aspecto Perfecto, o bien hay que considerar que el valor caracterizador básico de la perífrasis en latín es aspectualmente ambivalente, dada la evidente interacción entre imperfectividad y perfectividad.

En cualquier caso, la consideración de la lectura caracterizadora como valor originario de la construcción latina obligaría a replantearse el juego 
de inferencias que actúan en la construccionalización de soleo+INF y en la obtención de otros valores detectados. Por una parte, el valor caracterizador se sitúa en la base de la lectura genérica que aflora cuando se dan las condiciones de sujeto genérico y verbo estativo o pasivo (ejemplo 36, aquí citado como 60). Por otra parte, a partir de este valor originario, la presencia de marcas -morfológicas, sintácticas o léxicas- de frecuencia alta, propiciarían el desarrollo del valor habitual frecuentativo que más se ha generalizado en las lenguas modernas (8, aquí 61); a su vez, los marcadores de frecuencia baja invitarían valores modales epistémicos, indicativos de la posibilidad de no ocurrencia (13, aquí 62). Por último, en el plano temporal, los usos del auxiliar soleo en tiempos de pasado desplegarían valores tempoaspectuales de confinamiento en el pasado (51, aquí 63).

(60) qui mentiri solet, peierare consueuit. (Cicero, Pro Roscio Gallo comoedo 45)

'Quien suele mentir, acostumbra perjurar'.

(61) [...] saepe enim soleo audire Roscium (Cicero, De oratore 1, 129) 'suelo ir a escuchar a Roscio con frecuencia'

(62) ipsi qui Cynica traducunt tempora pera non numquam nummis uendere uerba solent. (Petronius, Satyrica 14, 2)

'incluso los que van por la vida con la alforja de los cínicos, a veces suelen vender las palabras por unas monedas'.

(63) dico unum ridiculum dictum de dictis melioribus, / quibus solebam menstrualis epulas anteadipiscier: / nemo ridet. (Plautus, Captiui 482)

'Digo uno de mis mejores chistes, con los que antes solía conseguir cenas para un mes: nadie se ríe'.

Así pues, los usos desplegados por soleo+INF en latín podrían representarse en forma de una estructura radial, puesto que sabemos que este es un modelo que no solo es aplicable a las categorías (Lakoff 1987) sino que permite observar regularidades en la motivación de significados (Brugman 1988). En nuestro esquema, el valor tipificador o caracterizador básico constituye el centro convencional, esto es, el significado central de la construcción léxica, a partir del cual distintos factores de orden morfológico, sintáctico y contextual actúan como principios de extensión hacia los significados periféricos relacionados. La asociación de las nuevas formas a los nuevos valores lleva consigo la creación de una red de construcciones gramaticales diferentes que hallan correspondencia en la categorización misma de la perífrasis, capaz de representar, como ya hemos señalado, no solo la clase 
aspectual más comúnmente admitida, sino también la tempo-aspectual e incluso la modal.

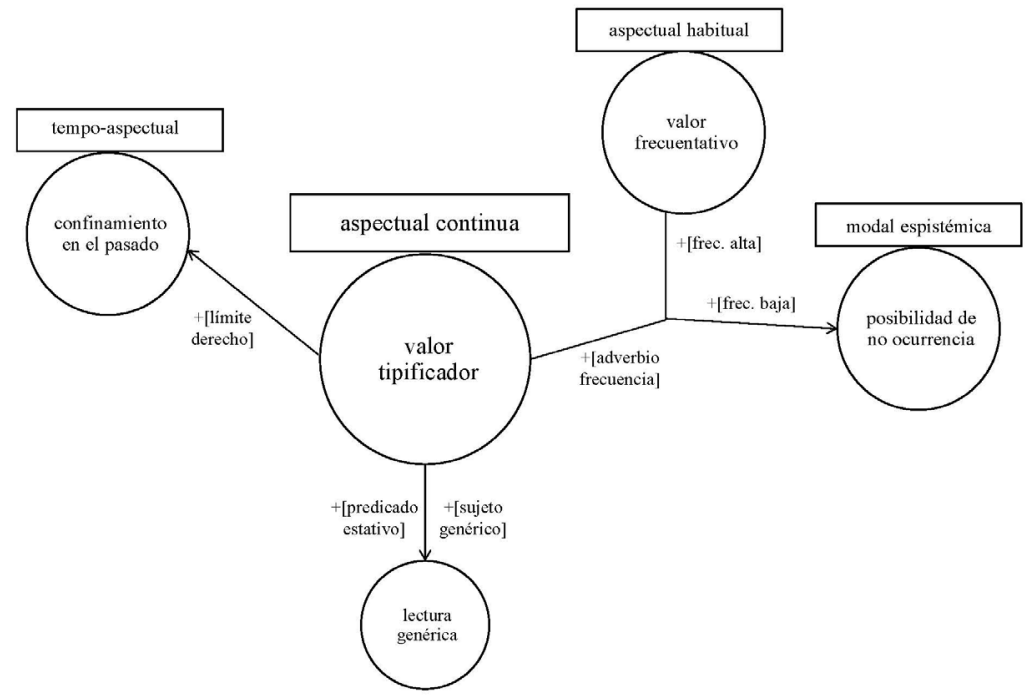

REFERENCIAS BIBLIOGRÁFICAS

Artigas, Esther y Laura Cabré. (en prensa). “AAcostumbraron los antiguos dezirlo así? Perfectividad y aspecto habitual en latín". En Mar Garachana (ed.). La evolución de las perifrasis verbales en español. Una aproximación desde la Gramática de construcciones diacrónica. Bern: Peter Lang.

Bassols de Climent, Mariano. 1956. Sintaxis latina, 2 vols. Barcelona: Instituto Antonio de Nebrija.

BarĐdal, Jóhanna y Spike Gildea. 2015. "Epistemological context, basic assumptions and historical implications". En Jóhanna Barđdal, Elena Smirnova Lotte Sommerer y Spike Gildea (eds.). Diachronic Construction Grammar, pp. 1-50. Amsterdam-Philadelphia: John Benjamins.

Bertinetto, Pier Marco. 1986. Tempo, aspetto e atione nel verbo italiano: II sistema dell' indicativo. Firenze: Accademia della Crusca.

1997. Il dominio tempo-aspettuale: Demarcazioni, intersezioni, contrasti. Torino: Rosenberg \& Sellier.

2004. "Estativos, progresivos, habituales". En Luis García Fernández y Bruno Camus (eds.). El pretérito imperfecto, pp. 273-316. Madrid: Gredos [= Bertinetto, Pier Marco. 1994. "Statives, Progressives, Habituals", Linguistics 32, 391-423]. 
Brugman, Claudia. 1988. The Story of over: Polysemy, Semantics, and the Structure of the Lexicon. New York: Garland.

CAmus, Bruno. 2004. "Perífrasis verbales y expresión del aspecto en español”. En Luis García Fernández y Bruno Camus (eds.). El pretérito imperfecto, pp. 511-572. Madrid: Gredos. 2011. "Estados y habitualidad: El caso de <soler+inf.>". En Ángeles Carrasco Gutiérrez (ed.). Sobre estados y estatividad, pp. 142-157. München: Lincom Europa.

Casado-Velarde, Manuel. 1983. "El verbo soler y los modales", Boletín de la Real Academia Española LXIII, 1, 67-76.

Diк, Simon C. 1997. The Theory of Functional Grammar. Part I: The Structure of the Clause, $2^{\text {a }}$ edición. Berlin - New York: Mouton de Gruyter.

Fernández de CAStro, Félix. 1999. Las perifrasis verbales en el español actual. Madrid: Gredos.

García FernándeZ, Luis. 2004. "El imperfecto en el sistema verbal español”. En Luis García Fernández y Bruno Camus (eds.). El pretérito imperfecto, pp. 13-95. Madrid: Gredos. (dir.). 2006. Diccionario de perifrasis verbales. Madrid: Gredos.

GAVARRó, ANNA y BRENDA LaCA. 2002. "Les perífrasis temporals, aspectuals i modals". En Joan Solà, M. Rosa Lloret, Joan Mascaró y Manuel Pérez Saldanya (eds.). Gramàtica del Català Contemporani, pp. 2663-2726. Barcelona: Empúries.

Giammatteo, Mabel, Ana María Marcovecchio e Hilda Albano. 2011. "Dos dominios en intersección: habitualidad y posibilidad. Su manifestación en las perífrasis verbales". En Juan Cuartero Otal, Luis García Fernández y Carsten Sinner (eds.). Estudios sobre perifrasis y aspecto, pp. 139-157. München: Peniope.

Goldberg, Adele Eva. 2006. Constructions at Work: The Nature of Generalization in Language. Oxford: Oxford University Press.

Gómez TorRego, Leonardo. 1999. "Los verbos auxiliares. Las perífrasis verbales de infinitivo". En Ignacio Bosque y Violeta Demonte (eds.). Gramática descriptiva de la lengua española, vol. 2, pp. 3323-3388. Madrid: Espasa.

Haverling, Gerd V. M. 2010. Actionality, tense and viewpont. En Philip Baldi y Pierluigi Cuzzolin (eds.), New Perspectives on Historical Latin Syntax 2. Constituent Syntax: Adverbial Phrases, Adverbs, Mood, Tense. Berlin-New York: De Gruyter Mouton, pp. 277-523.

Havu, JukKa. 1997. La constitución temporal del sintagma verbal en español. Helsinki: Academia scientiarum Fennica.

Klein, Wolfgang. 1982. “The Present Perfect Puzzle”, Language 68, 3: 525-552.

Lakoff, George. 1987. Women, Fire, and Dangerous Things: What Categories Reveal about the Mind. Chicago: University of Chicago Press.

Lenci, Alessandro. 1995. "The Semantic Representation of Non-Quantificational Habituals". En Pier Marco Bertinetto, Valentina Bianchi, Jim Higginbotham y Mario Squartini (eds.). Temporal Reference, Aspect and Actionality, pp. 143-158. Torino: Rosenberg \& Sellier.

Lenci, Alessandro y Pier Marco Bertinetto. 2000. "Aspect, adverbs, and events: habituality vs. perfectivity". En James Higginbotham, Fabio Pianesi y Achille C. Varzi (eds.). Speaking of Events, pp. 245-287. Oxford: Oxford University Press.

Manfredini, Adriana. 2016. "Auxiliaries within comparative clauses: some remarks concerning their syntax and grammatical description: Descriptive and Historical Accounts for the Latin Language". En Paolo Poccetti (ed.). Latinitatis rationes, pp. 262-276. BerlinBoston: Walter de Gruyter.

MontSERRAT, SANDRA (en prensa). "A diachronic analysis of the periphrasis soler + infinitive in Catalan: a test-case of invited inferencing". En Mar Garachana, Sandra Montserrat y Claus Pusch (eds.). From composite predicates to verbal periphrases in Romance languages, Amsterdam: John Benjamins. 
Olbertz, Hella. 1998. Verbal Periphrases in a Functional Grammar of Spanish. Berlin-New York: Mouton de Gruyter.

Pinkster, Harm. 2015. The Oxford Latin Syntax. Volume 1: The simple clause. Oxford: Oxford University Press.

Squartini, Mario. 2010. "XIII: Il verbo". En Giampaolo Salvi y Lorenzo Renzi (eds.). Grammatica dell'italiano antico, vol. I, pp. 511-547. Bologna: Il Mulino.

Traugott, Elizabeth Closs y Graeme Trousdale. 2013. Constructionalization and Constructional Changes. Oxford: Oxford University Press.

Uría MaQua, IsABel. 1978. "Sobre la gramaticalización del modal soler en textos de clerecía de los siglos XIII y XIV". En Estudios ofrecidos a Emilio Alarcos Llorach, vol. 3, pp. 313-336. Oviedo: Universidad de Oviedo.

VATRICAN, AXelLe. 2015. "Sobre la perífrasis soler + verbo estativo: una lectura genérica", Borealis: An International Journal of Hispanic Linguistics 4/2, 104-118.

YlLera, Alicia. 1980. Sintaxis histórica del verbo español: las perifrasis medievales. Zaragoza: Universidad de Zaragoza.

\section{FUENTES DE DATOS}

CDL: Cross Database Searchtool, Brepolis Library of Latin Texts Series A - B,Turnhout, Brepols http://www.brepolis.net

CORDE: Real Academia Española, Corpus diacrónico del español http://www.rae.es DLD: Database of Latin Dictionaries, Turnhout, Brepols http://www.brepolis.net Gradia: Corpus de Gramática y Diacronía (http://Gradiadiacronia.wix.com/Gradia)

Hispanic Seminary of Medieval Studies (Madison), Biblioteca Digital de Textos del Español Antiguo http://www.hispanicseminary.org/textconc-es.htm

Pнг: The Packard Humanities Institute, Classical Latin Texts http://latin.packhum.org

ThLL (1900 - ): Thesaurus linguae Latinae, Teubner, Stuttgart - Leipzig (electronic resource CD, K.G. Saur - Walter de Gruyter). 